\title{
REFLEXÕES SOBRE A RELAÇÃO ENTRE A EXPANSÃO IMOBILIÁRIA E A PRODUÇÃO DO ESPAÇO DO MUNICÍPIO DE CAMPO MOURÃO (PR), BRASIL
}

\section{REFLECTIONS ON THE RELATION BETWEEN HOUSING EXPANSION AND THE PRODUCTION OF SPACE IN CAMPO MOURÃO (PR), BRAZIL}

\author{
Marcos Clair Bovo \\ Universidade Estadual do Paraná/Campus de Campo Mourão - Campo Mourão \\ - PR - Brasil \\ Solange Aparecida Loch \\ Universidade Estadual do Paraná/Campus de Campo Mourão - Campo Mourão \\ - PR - Brasil \\ Juliano Domingues da Silva \\ Universidade Estadual de Maringá - Maringá - PR - Brasil
}

\begin{abstract}
Resumo: O espaço urbano apresenta um processo dinâmico de transformação que é influenciado, com maior ou menor intensidade, pelos proprietários dos meios de produção, proprietários de terras, promotores imobiliários, o Estado e grupos sociais excluídos. Esta pesquisa tem por objetivo demonstrar que a produção do espaço urbano e a expansão imobiliária em Campo Mourão - PR, Brasil, foram estimuladas pelo financiamento público, em especial o Programa Minha Casa Minha Vida - PMCMV do governo federal, contribuindo para a produção do espaço urbano com fins de especulação imobiliária e provocando a segregação espacial. Por meio da utilização de mapas da área urbana do município, imagens aéreas dos bairros Jardim Albuquerque e Conjunto Cohapar, e indicadores habitacionais do Censo Demográfico 2010 do Instituto Brasileiro de Geografia e Estatística - IBGE, foi possível observar a influência do financiamento público sobre a produção do espaço urbano de Campo Mourão, o que provocou um aumento na valorização dos imóveis, aumentando a segregação espacial.
\end{abstract}

Palavras-chave: Produção do Espaço. Segregação Espacial. Financiamento Público. Especulação Imobiliária. 
Abstract: The urban space has a dynamic process of transformation that is influenced, with a greater or lesser intensity, by the owners of the means of production, land owners, property developers, the state and excluded social groups. This research aims at demonstrating that the production of urban space and the housing expansion in Campo Mourão (PR), Brazil, were stimulated by public funding, in particular the Program Minha Casa Minha Vida, implemented by the Federal Government, contributing to a production of urban space with the purpose of speculation, and leading to spatial segregation. Through the use of maps of the urban area, aerial images of the districts Jardim Albuquerque and Conjunto Cohapar, and indicators of the Demographic Census performed by IBGE in 2010, it was observed that public funding has influenced the production of urban space in Campo Mourão, causing an increase in real estate values, leading to spatial segregation.

Keywords: Production of Space. Spatial Segregation. Public Funding. Housing Speculation.

\section{INTRODUÇÃO}

Os estudos que buscam a compreensão do espaço urbano são enriquecidos pela Geografia, que possui o papel de analisar e entender a construção do espaço geográfico por meio das relações sociais. Dado o processo de globalização que permeia a sociedade atual, Machado e Mendes (2012, p. 103) afirmam que "as cidades passaram a ser tratadas como empresas associadas ao processo produtivo destinado ao mercado mundial". Compans (2005) corrobora essa assertiva, destacando que as grandes cidades têm cada vez mais traços comuns com grandes empresas, pois dependem dos mesmos fatores econômicos, são confrontadas com uma concorrência internacional e gerenciam serviços, atividades de produção e recursos humanos.

Dessa forma, para ter uma ideia mais fidedigna de como ocorre a dinâmica da cidade e a produção do espaço, os pesquisadores podem lançar mão de estudos a partir de um ponto de vista da Geografia em associação com estudos econômicos, buscando uma complementariedade dos campos de pesquisa. A partir dessa premissa, este estudo procura analisar a questão habitacional e a participação do poder público, contribuindo para a produção do espaço urbano de Campo Mourão. Assim, pretende-se verificar a expansão e, consequentemente, a especulação imobiliária, estimulada pelo 
financiamento público habitacional, em especial o PMCMV, lançado em 2009 pelo governo federal. Pretende-se, também, entender os possíveis efeitos gerados pelo financiamento habitacional, como a segregação espacial.

\section{CONSIDERAÇÕES GERAIS SOBRE A PRODUÇÃO DO ESPAÇO E A EXPANSÃO IMOBILIÁRIA}

As cidades, conforme destaca Carlos (2005), são consideradas como um produto da divisão social do trabalho e do poder nela centralizados e, em cada período histórico, assumem dinâmicas diferenciadas, com formas e funções distintas. A partir dos últimos anos do século XX e início do século XXI, profundas transformações sociais e econômicas ocorreram, decorrentes da concretização de desenvolvimentos tecnológicos que estimularam o processo de reestruturação do sistema capitalista de produção, principalmente na organização das cidades e de seus espaços intraurbano (CASTELLS, 1999).

Nesse sentido, é importante destacar que o espaço urbano é "fragmentado, articulado, reflexo e condicionante social, cheio de símbolos e campo de lutas. É um produto social, resultado de ações acumulativas através do tempo engendradas por agentes que produzem e consomem espaço [...]" (CORRÊA, 2002, p. 11). A produção desse mosaico que é o espaço urbano se dá de forma bastante complexa, tendo como principais agentes o poder público e/ou Estado nas suas variadas instâncias (federal, estadual e municipal), o setor privado (grandes empresas, agentes fundiários, agentes imobiliários e outros) e a sociedade civil (CORRÊA, 2002).

Dessa forma, verifica-se que a produção do espaço capitalista resulta das ações da sociedade e, nessa perspectiva, Lefebvre (2008) argumenta que a produção do espaço é um produto da história, e em todos os níveis de produção se faz necessário compreendê-lo enquanto resultante de fenômenos sociais e políticos. Para o autor:

a produção do espaço não pode ser comparada à produção deste ou daquele objeto particular, desta ou daquela mercadoria. E, no entanto, existem relações entre a produção das coisas e a produção do espaço para geri-lo, para explorálo (LEFEBVRE, 2008, p. 62). 
Nesse sentido, para compreender o conceito do espaço no contexto do modo capitalista de produção, é preciso perceber que este tem um valor econômico e político. A busca incessante pelo lucro, premissa básica do modo de produção capitalista, no qual a racionalidade econômica norteia todas as relações de produção, também interfere na questão habitacional, fazendo com que as relações de compra e aquisição de imóveis tenham um caráter de exploração (VILLAÇA, 1986).

Desse modo, conforme destacam Postali e Mendes (2011), não só no Brasil, como nos demais países regidos pelo sistema capitalista, a terra - especialmente a urbana - e as edificações sobre ela integram o quadro daquilo que o capital denomina de "mercadoria". Consequentemente, $\mathrm{o}$ acesso à terra só pode ser realizado mediante a compra de um direito de propriedade ou mediante o pagamento de um aluguel periódico (SINGER, 1979).

Diante disso, a propriedade privada se apresenta como um entrave para o desenvolvimento da sociedade, pois o acesso à terra exige uma renda monetária, e o sistema capitalista não assegura um mínimo de renda a todos, conforme afirmam Postali e Mendes (2011).

Costa (2011) também contribui com esse argumento, destacando que, desde o surgimento da economia de mercado, os baixos salários resultantes da concorrência entre os trabalhadores e a existência de desemprego impedem que os mesmos obtenham meios imprescindíveis à reprodução de sua capacidade de trabalho.

Ainda nesse contexto, pode-se entender a habitação como um bem econômico distinto dos demais bens, conforme afirmação de D'Amico (201 1, p. 38):

como bem econômico, é necessário um esforço considerável por parte das famílias para adquiri-lo, pois elas alocam boa parte da renda atual e futura em sua aquisição, independentemente da classe social em que essas famílias se situam. Isso porque as famílias de maior renda tendem a adquirir imóveis de maior valor para atender às suas necessidades familiares, à construção de um patrimônio, como investimento para especulação ou simplesmente por status social. 
Corrobora essa afirmativa a Pesquisa de Orçamentos Familiares de 2008-2009, realizada pelo IBGE, na qual se verifica que as famílias com renda de até dois salários mínimos gastam $37,2 \%$ da renda com despesas de moradia, enquanto as famílias que ganham mais de 15 salários mínimos destinam $25,1 \%$ da sua renda para esse tipo de despesa. É possível notar que as famílias de baixa renda são aquelas que mobilizam mais recursos para esse bem.

Para Bastos (2001), o problema habitacional deveria ser tratado a partir de ações transformadoras da ordem social que as originou e, consequentemente, o Estado deveria atuar de maneira eficaz na promoção de moradias populares.

No mesmo caminho, D'Amico (2011) destaca que uma política nacional de habitação deve abordar a questão econômica do déficit habitacional, alterando o modelo institucional e econômico de financiamento da casa própria vigente no país - ao menos para as famílias de baixa renda, aquelas que têm as maiores necessidades e dificuldades no acesso à moradia -, seja pela concessão de subsídios, isenção de impostos ou qualquer outro tipo de intervenção econômica.

Nesse contexto, surgiram os programas de financiamento público para a habitação, que, ao longo do tempo, foram criados com o intuito de contribuir para que a população das classes com renda mais baixa adquirissem a casa própria. Contudo, também contribuíram para a produção do espaço urbano cada vez mais segregado.

A primeira iniciativa brasileira voltada para a construção de casas populares para as classes de baixa renda foi a criação da Fundação da Casa Popular em 1946 (AZEVEDO, 1988). A motivação inicial implícita nesse programa era o ganho político advindo de ações populistas junto à classe trabalhadora, que já era expressiva no cenário nacional da época (AZEVEDO; ANDRADE, 2011). A Fundação Casa Popular tinha como objetivo a construção de moradias, o financiamento de obras de infraestrutura urbana, assistência social, financiamento de indústrias da construção civil e pesquisas habitacionais (BONDUKI, 1994).

As metas ambiciosas da Fundação Casa Popular ficaram longe de ser alcançadas, pois esbarraram na falta de experiência do órgão para realizar ações distintas de maneira conjunta e, principalmente, pela ausência de recursos que viabilizassem o programa (AZEVEDO; ANDRADE, 2011). Além disso, o processo de construção das moradias, 
por contar com contrapartida dos municípios atendidos, foi permeado por vícios como o clientelismo e paternalismo autoritário (AZEVEDO; ANDRADE, 2011). Por um lado, as decisões sobre as construções se guiavam por uma ótica clientelista na qual o local da construção, a seleção e a classificação dos candidatos beneficiados eram pautadas por interesses pessoais, seja privilegiando pessoas próximas aos agentes públicos ou beneficiando áreas com interesses privados para a especulação imobiliária. Por outro lado, a intervenção do Estado extrapolava o financiamento de recursos e assumia uma posição paternalista autoritária, pois as pessoas beneficiadas pelas moradias deveriam obedecer a contratos que também impunham normas de conduta social regidas pelo Estado, e o cumprimento de pagamento do financiamento ficava em segundo plano (AZEVEDO; ANDRADE, 2011).

A dificuldade para cumprir os objetivos da Fundação Casa Popular fez com que o Estado realizasse uma nova estratégia de política intervencionista para solucionar o déficit habitacional, criando o Sistema Financeiro de Habitação - SFH e o Banco Nacional da Habitação - BNH, no ano de 1964 (AZEVEDO; ANDRADE, 2011). Nesse momento, o governo federal procurou formular uma política nacional de habitação e coordenar as ações públicas e privadas para estimular a construção civil e o financiamento imobiliário. O governo militar, no intuito de conquistar o apoio popular, investiu maciçamente nos primeiros cinco anos do programa, beneficiando em grande parte a classe de baixa renda (AZEVEDO; ANDRADE, 2011). Contudo, devido à baixa rentabilidade dos investimentos para a classe baixa, que contavam com juros baixos e inadimplência alta, com o tempo, o governo passou a direcionar os investimentos para a classe média (AZEVEDO, 1988). Desse modo, durante o período militar, o programa do BNH não conseguiu de fato resolver o problema habitacional do Brasil, que se concentrava nas populações da classe baixa.

A partir de 1986, após a extinção do BNH, o Conselho Monetário Nacional - CMN assumiu a função de orientar, disciplinar e controlar os agentes participantes do SFH, cujas aplicações de recursos mostraramse inadequadas, desestimulando o financiamento de imóveis até entre as camadas sociais de renda média. Essa situação provocou um movimento de "elitização" dos financiamentos imobiliários, uma vez que a maior parte dos recursos do FGTS foi utilizada para financiar as 
moradias das famílias com renda acima de cinco salários mínimos (D'AMICO, 2011 ).

$\mathrm{Na}$ década de 1990, os governos Collor e Fernando Henrique Cardoso (FHC) também pouco contribuíram para resolver o problema do déficit habitacional. No governo Collor, diante da preocupação com a redução da inflação, os programas habitacionais ficaram em segundo plano, contando com algumas ações restritas voltadas para o subsídio de construção de moradias para a classe média com fundos do Fundo de Garantia do Tempo de Serviço - FGTS, mas que não lograram êxito como o planejado, em razão da falta de planejamento financeiro e porque persistia a influência do clientelismo e lobby de setores industriais da construção civil (AZEVEDO, 2007).

No governo FHC, inicialmente se propôs um plano amplo de subsídios para a habitação, que contava com fortalecimento do fundo do FGTS para ampliar a capacidade de investimento e a criação de novas formas de captação de fundos (AZEVEDO, 2007). Nesse bojo, a contribuição com maior relevância do governo FHC foi criar o Sistema Financeiro Imobiliário - SFI, que operava com fundos da caderneta de poupança (iniciativa privada nacional e internacional) e o FGTS. Além da novidade de contar com recursos da iniciativa privada, esse sistema implementou a alienação fiduciária, pela qual o mutuário só se tornava proprietário do imóvel ao final do pagamento do financiamento, facilitando a recuperação imediata do imóvel em caso de inadimplência (AZEVEDO, 2007).

Nesse programa, os contratos eram realizados entre os agentes fiduciantes e fiduciários, que celebravam o contrato sem a intervenção do Estado, e os trabalhadores assalariados poderiam utilizar o FGTS como parte do pagamento do imóvel. Azevedo (2007) destaca que esse programa contribuiu para viabilizar um aumento da produção habitacional, mas ficou longe de atender as parcelas da população com renda mais baixa, devido aos valores mais altos dos financiamentos, determinados pelo contexto de juros mais altos, que visavam exclusivamente a retribuir o investimento da iniciativa privada.

Desse modo, D'Amico (2011) demonstra que os financiamentos habitacionais até o final dos anos 2000 não foram suficientes para amenizar os altos índices de déficit habitacional. Assim, com o objetivo de facilitar e possibilitar o acesso à moradia para um público com renda 
baixa, o governo federal criou, em 2009, o PMCMV, que tem como objetivo principal criar mecanismos de incentivo à produção e à aquisição de novas unidades habitacionais pelas famílias com renda de até 10 salários mínimos:

[...] na concepção de desenvolvimento através da liberdade elaborada por Amartya Sen, o acesso à moradia é visto como condição para a promoção das liberdades dos indivíduos e, consequentemente, para o desenvolvimento do país. Por esta razão, foi implantado em 2009 o Programa Minha Casa, Minha Vida (PMCMV), cujo objetivo principal é facilitar a aquisição da casa própria pelas famílias com renda mensal entre zero e dez salários mínimos, sobretudo por aquelas localizadas nas periferias das grandes cidades (D'AMICO, 2011, p. 33).

Os recursos financeiros para o programa são garantidos pela União e são oriundos de diversas fontes e fundos, que são concedidos por meio de empréstimos diretos ao comprador, por meio de financiamento para os promotores imobiliários ou diretamente para os governos municipais (D'AMICO, 2011). Assim, verifica-se que a origem dos recursos do PMCMV é pública, formada pela contribuição dos impostos e demais taxas cobradas do contribuinte.

Em relação ao aumento do financiamento por meio do PMCMV, D'Amico (2011) destaca que os empréstimos habitacionais passaram de R\$ 70,3 bilhões em 2009 para R\$ 106,1 bilhões em 2010, ou seja, houve um aumento de $R \$ 18,7$ bilhões em apenas um ano. Com base nesses valores e, sabendo-se que o nível de financiamentos imobiliários da Caixa foi de $\mathrm{R} \$ 86,9$ bilhões, de acordo com o demonstrativo contábil do primeiro semestre de 2010 , percebe-se que a Caixa é responsável por mais de $81 \%$ dos empréstimos habitacionais do país, em termos de montante financeiro (D'AMICO, 2011 ).

Cabe ressaltar, sem se aprofundar sobre as leis econômicas, que esse aumento no crédito para o financiamento habitacional provoca um aumento da demanda por imóveis, fazendo com que os preços dos imóveis tenham uma valorização. Dessa forma, faz-se necessário entender como o solo (imóveis) adquire valor. Conforme observado anteriormente, o mecanismo essencial de produção da cidade capitalista baseia-se no princípio econômico da busca do máximo benefício.

Ferreira (2001, p. 36) afirma que: 
[...] o solo, bem escasso e de uso necessário para todos, é convertido em valor de troca, ao aplicar-se capital e trabalho mediante a urbanização e a construção. Os elementos da cidade (solo, edifícios, habitações) convertem-se em mercadoria, comercializada como qualquer outra, com preços fixados pela lei da oferta e demanda. Desta maneira, a propriedade privada, fundamento do modo de produção capitalista, se beneficia do valor de troca e se apropria dos valores que a coletividade cria na cidade através da urbanização. As contínuas transformações da paisagem urbana também são consequência da busca do máximo benefício pelo capital.

Para Ferreira (2001), o argumento é de que a propriedade privada do solo urbano proporciona renda para quem a detém, ou seja, o solo urbano tem a capacidade de gerar renda, reproduzindo seu valor e mais um valor excedente, que aparece para o proprietário sob a forma de lucro. Entretanto, a autora pondera que esse capital imobiliário é um falso capital. Apesar de se valorizar, essa valorização não é a atividade produtiva, mas o monopólio do acesso a uma condição indispensável àquela atividade. Assim, "o solo assume um valor por ser necessário à produção capitalista, como espaço onde a atividade humana se realiza, e estar sob o monopólio do proprietário" (FERREIRA, 2001, p. 37).

De acordo com Santos (2005), na economia urbana há a economia dos pobres e a economia dos ricos, que constituem circuitos distintos. Nesse caso, as áreas mais valorizadas são aquelas que se aproximam dos pontos de consumo e trabalho das camadas sociais com melhores condições de educação e renda.

Para compreender os fatores que levam à formação desse valor, cabe destacar que as aglomerações urbanas são constituídas por diversas localizações, que têm a acessibilidade como um dos principais atributos, com grande influência na valoração do lote urbano. As localizações intraurbanas, que minimizam o conjunto dos tempos de deslocamento diário de pessoas, tais como os trajetos casa-trabalho, casa-lazer, casa-escola, casa-consumo, dentre outros, são mais valorizadas (FERRAUDO; LOUZADA-NETO; FERREIRA, 2010, p. 53).

Sobre o financiamento imobiliário e a formação do valor dos imóveis, destaca-se o trabalho de Machado e Mendes (2012), no qual os autores afirmam que o aquecimento do mercado imobiliário e a rapidez 
para a sua comercialização são determinados pelo preço, localização, conservação e segurança do bairro. Os autores refletem sobre a facilidade do financiamento da casa própria, ressaltando o papel do PMCMV, que, desde que foi lançado em 2009, aqueceu o mercado imobiliário em todo o país, onde os preços já estavam pressionados, e o programa acabou servindo para aumentar a valorização sem controle dos imóveis. Os autores concluem que até os próprios agentes do mercado imobiliário do município em estudo desconfiam do preço cobrado pelos imóveis, pois os mesmo não correspondem à realidade, crescendo de forma oportunista diante da grande procura por moradia.

Diante desse cenário, cabe destacar que os promotores imobiliários, ou pessoas que se aventuram como especuladores, adquirem imóveis para revendê-los posteriormente, com a finalidade de ter um ganho pela especulação. Essa ação provoca a criação de vazios urbanos, pois os especuladores compram os terrenos e os seguram, esperando a valorização. Os bairros mais valorizados apresentam uma baixa densidade demográfica. Conforme destacam Portella et al (2003), as baixas densidades da maioria das regiões das cidades podem ser atribuídas aos vazios urbanos derivados tanto da ação de proprietários particulares, que os reservam por longos períodos de tempo, como propriedades públicas ou de empresas estatais, que os mantêm, às vezes, por décadas sem ser utilizados.

A manutenção dessas áreas vazias no interior da cidade acaba favorecendo um aumento da periferia, ou seja, ocupação de áreas cada vez mais distantes do centro e dos principais equipamentos urbanos. Essa situação também força o Poder Público a investir em áreas cada vez mais distantes, o que encarece e dificulta a oferta de infraestrutura urbana.

Em relação a esse tema, Ribeiro (2003, p. 165) destaca duas abordagens. Na primeira, o autor apresenta a segregação como uma diferença de localização espacial de um grupo em relação a outros grupos, cujo eixo central é a "distância social" expressa na "distância espacial", como resultado das ações e escolhas dos próprios indivíduos que buscam se agrupar, contrariando a ideia (utópica) de mistura social. $\mathrm{Na}$ segunda abordagem, a segregação é compreendida como as diferenças sociais na ocupação do espaço urbano dadas pelas 
possibilidades distintas de acesso à cidade, que refletem, em última instância, a estrutura da própria sociedade desigual.

Outro conceito de segregação social é dado por Sabatini e Sierralta (2004):

a segregação social do espaço urbano, ou segregação residencial, apresenta, a nosso ver, três dimensões principais: a) a tendência de certos grupos sociais em concentrar-se em algumas áreas da cidade; b) a conformação das áreas com alto grau de homogeneidade social; e c) a percepção subjetiva que se forma sobre o que é segregação "objetiva" (as duas primeiras dimensões), tanto para os que pertencem a bairros ou grupos segregados, como para os que estão fora deles.

Os autores Sabatini e Sierralta (2004) destacam a importância de se conhecer, em cada cidade, a relação entre segregação e outros processos ou mecanismos, tanto por atuarem estimulando a segregação como por operarem com suas consequências, incluindo-se entre elas a venda e compra de terras.

Segundo Corrêa (2002), a dinâmica da segregação da cidade é marcada, inicialmente, pela concentração da elite junto ao centro, enquanto na periferia vivem os pobres. À medida que a cidade se desenvolve, devido à maior concentração na zona central de atividades, instituições e tráfego, a elite progressivamente tende a abandonar o centro, que se desvaloriza no quesito da moradia, em direção a aprazíveis subúrbios. A partir daí, a segregação espacial pode assumir um padrão em setores a provir do centro. As áreas residenciais de maior estrato social localizam-se no setor de maiores amenidades, e se expandem ao longo de um eixo de circulação que corta as melhores áreas da cidade em direção ao centro, encontrando-se cercadas pelos setores da população de médio estrato. A partir de sua ação, estabelecem-se os demais grupos sociais em outros setores.

\section{PRODUÇÃO DO ESPAÇO E EXPANSÃO IMOBILIÁRIA NO MUNICÍPIO DE CAMPO MOURÃO}

Campo Mourão é um município do Estado do Paraná localizado a $24^{\circ} 02^{\prime} 38^{\prime \prime}$ de latitude sul e a 52 $22^{\prime} 40^{\prime \prime}$ de longitude oeste do 
Meridiano de Greenwich, com uma altitude média de 630 metros acima do nível do mar.

$\mathrm{Na}$ divisão territorial do IBGE, Campo Mourão integra a Microrregião de Campo Mourão, composta por 14 municípios. Esta, por sua vez, insere-se na Mesorregião Centro Ocidental Paranaense, composta por 25 municípios, compreendendo uma área total de $11.913,7 \mathrm{Km}^{2}$. Com 87.194 habitantes (IBGE, 2010) e área terrestre de $783,67 \mathrm{Km}^{2}$, Campo Mourão é o maior polo econômico e demográfico da Mesorregião Centro Ocidental Paranaense, e estende sua influência sobre os demais municípios da Meso. Tem densidade populacional de 115,05 hab. $/ \mathrm{Km}^{2}$, superior à média do Estado do Paraná $(47,96$ hab./ $\left(\mathrm{Km}^{2}\right)$.

Num primeiro momento, será estudada a expansão imobiliária de toda a área urbana do Município de Campo Mourão, e depois será estudado o caso da segregação dos bairros Conjunto Cohapar e Jardim Albuquerque, conforme se observa na figura 1. 
Figura 1.Área de Estudo

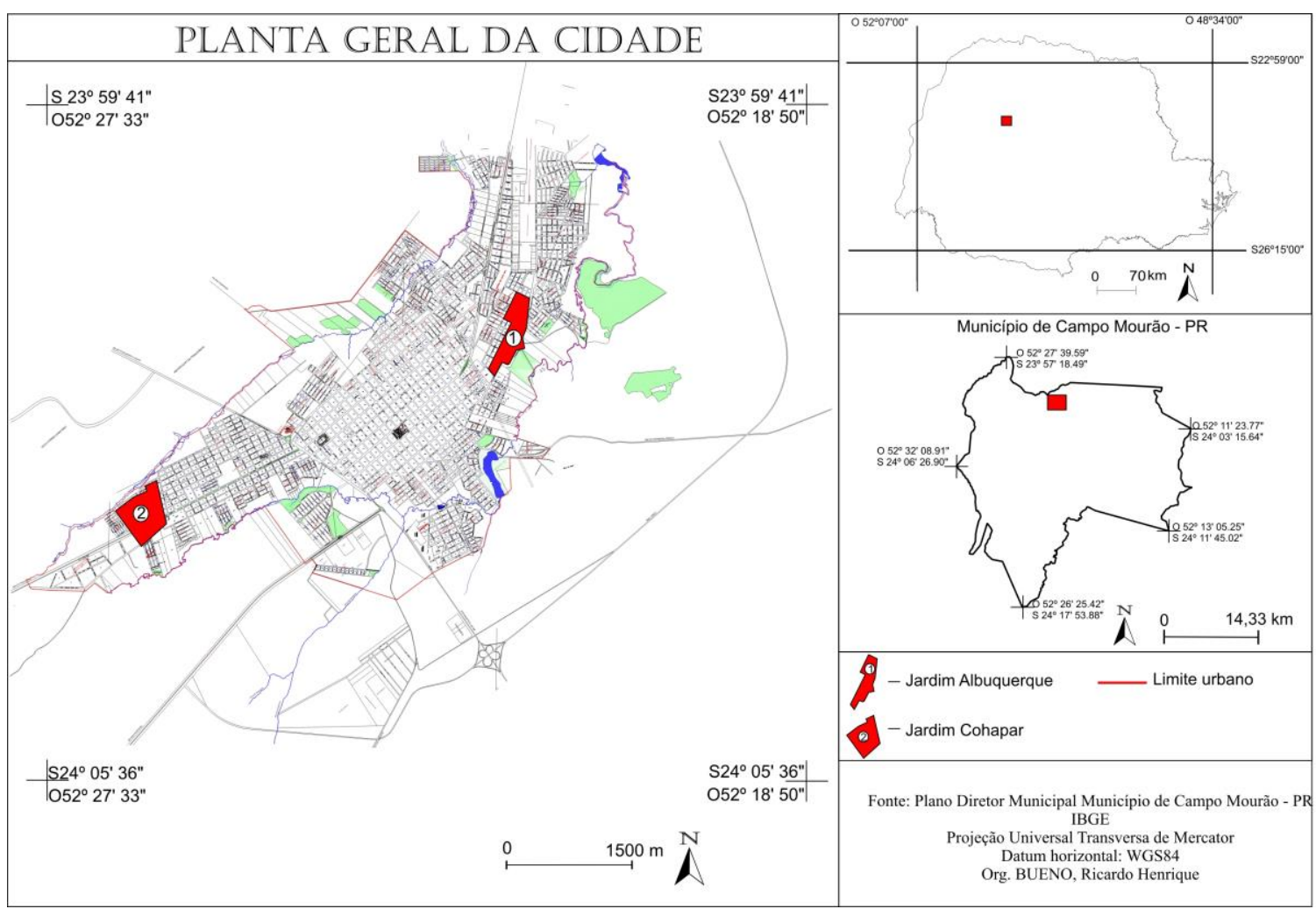

Fonte: Adaptado de Plano Diretor Municipal de Campo Mourão (2007).

O ritmo de crescimento demográfico previsto no Plano Diretor de 2007 do Município de Campo Mourão para o ano de 2017 estima uma demanda urbana para cerca de duas mil pessoas. Como é destacado no plano diretor, essa população poderia ser absorvida nos 4 mil lotes urbanos vazios já existentes no município. Dessa forma, esta pesquisa argumenta que a expansão imobiliária, incentivada com o financiamento habitacional PMCMV, fez com que o espaço urbano do município se alterasse de forma drástica, possibilitando o aumento da segregação espacial.

Como observado no plano diretor, o município já continha uma quantidade de lotes sem edificações que permitiriam absorver o crescimento demográfico, além da possibilidade de verticalização das construções. Contudo, o aumento da demanda de pessoas com poder de compra para aquisição de imóveis, incentivado pela facilidade no acesso ao crédito do PMCMV, provocou uma especulação imobiliária dos proprietários dos lotes vazios, que aumentaram o valor dos seus imóveis. Assim, investidores encontraram a oportunidade para lançar novos loteamentos, com o intuito de absorver essa demanda. Para 
viabilizar esses novos loteamentos, foi necessário um avanço da área urbana sobre a área rural, adentrando os limites do Rio do Campo e do Rio 119, que envolvem o município, além de criarem loteamentos afastados do centro e, consequentemente, dos serviços públicos básicos.

Para a comprovação empírica da influência do financiamento público habitacional na produção do espaço do Município de Campo Mourão, foram utilizados dados secundários obtidos na Secretaria de Planejamento da Prefeitura Municipal de Campo Mourão e Caixa Econômica Federal. Além disso, foram obtidos mapas da área urbana do município para realizar uma análise do espaço da cidade depois da criação do PMCMV.

Para evidenciar a correlação entre o financiamento público habitacional e o aumento na criação de novos bairros, foi utilizado o coeficiente de correlação de Pearson. Conforme Hair et al (2005), esse coeficiente é uma medida do grau de relação linear entre duas variáveis quantitativas, e varia entre os valores -1 e +1 . O valor 0 (zero) significa que não há relação linear; o valor +1 indica uma relação linear perfeita; e o valor - 1 também indica uma relação linear perfeita, mas inversa, ou seja: quando uma das variáveis aumenta, a outra diminui. Quanto mais próximo estiver de +1 ou -1 , mais forte é a associação linear entre as duas variáveis. Para medir a correlação entre as variáveis, foi utilizado o software de análise estatística multivariada IBM SPSS v.20.

Para a comprovação empírica da presença de vazios urbanos e da segregação social, foram escolhidos dois bairros do Município de Campo Mourão para realizar uma comparação: Jardim Albuquerque, tido como área de alto padrão, ocupado por classes sociais mais altas, e Jardim Cohapar, tido como área de baixo padrão, ocupado por classes sociais mais baixas.

A comprovação dos vazios urbanos se deu pela comparação visual dos mapas dos bairros obtido na plataforma do site Google.

Também foram obtidos, junto à Comissão de Avaliação de Valores Venais de Imóveis do Município Campo Mourão', os valores médios dos

\footnotetext{
1 Lei complementar n. 19/2010, art. 118, § $1^{\circ}$ : Fica instituída uma Comissão de Avaliação de Valores Venais de Imóveis, formada por 5 (cinco) membros, sendo 2 (dois) membros dentre servidores efetivos do Município, 2 (dois) membros indicados pelo Conselho Regional de Corretores de Imóveis - CRECI - PR, e pelo Secretário da
} 
terrenos dos dois bairros analisados, no período de 2000 a 2012, e os valores médios do Índice Nacional da Construção Civil do Estado do Paraná, no mesmo período. A partir desses dados, por meio do Coeficiente de Correlação de Pearson, foi possível identificar a valorização que os bairros tiveram, e como ela está correlacionada com o lançamento do PMCMV.

Os métodos para medir a segregação são variados e complexos. A forma mais usual é por meio da comparação da renda da população de uma determinada área com outras áreas. Entretanto, a informação sobre a renda é complexa e de difícil acesso, pois o IBGE não disponibiliza informações sobre renda por setores censitários para o Município de Campo Mourão.

Outra forma de se constatar a segregação é por meio da verificação da disponibilidade de acesso aos equipamentos urbanos, como escolas, unidades de atendimento à saúde, saneamento, transporte público, condições das moradias. A segregação é evidenciada quando um bairro possui acesso a esses equipamentos em detrimento de outro. Nesse caso, este último é segregado. No entanto, como Campo Mourão é um município de médio porte, os equipamentos urbanos são disponibilizados para todos os bairros. Além disso, conforme destaca Corrêa (2002), a segregação pode ser desejada por classes que optam pela separação ou imposta às classes mais baixas. Assim, alguns bairros do município, como é o caso do Jardim Albuquerque, não contam com a maioria dos equipamentos urbanos citados, mas não deixam de ser bairros considerados de alto padrão.

A forma escolhida para medir a segregação social, neste trabalho, é a observação (ou análise) da densidade demográfica e da densidade habitacional. Segundo Kran e Ferreira (2006), o conforto domiciliar possui reflexos diretos na qualidade de vida das pessoas. Dessa forma, as análises dos indicadores das condições de habitação são importantes, pois revelam as condições desses domicílios.

Ainda Segundo Kran e Ferreira (2006), a densidade demográfica é determinada pela razão entre o número total de moradores por hectare, e a densidade habitacional é determinada pela razão entre o número total de unidades domiciliares por hectares. O cálculo da densidade

Fazenda e Administração, sendo presidida por este, para propor a revisão dos valores imobiliários dos imóveis localizados em Campo Mourão. 
demográfica é realizado por meio da divisão do número de habitantes de uma determinada área pelo total de hectares daquela área, e a densidade habitacional é determinada pelo número de unidades habitacionais dividido pelo número de hectares. Os dados secundários para a realização dos cálculos foram obtidos no Censo Demográfico de 2010 do IBGE.

Para analisar a produção do espaço urbano conforme as condições citadas acima, foi realizado um comparativo do crescimento demográfico do IBGE, do crescimento espacial em hectares e o número de bairros criados no município. Conforme a tabela 1, pode-se acompanhar essa evolução no período de 1990 a $2012^{2}$.

Tabela 1. Crescimento populacional, espacial e bairros 1990/2012

\begin{tabular}{cccc}
\hline $\begin{array}{c}\text { Ano contagem da } \\
\text { população - IBGE }\end{array}$ & $\begin{array}{c}\text { Número de } \\
\text { Habitantes }\end{array}$ & Hectare - área urbana & $\begin{array}{c}\text { Número de } \\
\text { Bairros }\end{array}$ \\
\hline 1991 & 82.318 & $1.725,83$ & 71 \\
2000 & 80.476 & $1.895,32$ & 91 \\
2007 & 82.530 & $1.943,32$ & 104 \\
2010 & 87.194 & $2.012,76$ & 115 \\
2012 & 88.209 & $2.083,34$ & 139 \\
\hline
\end{tabular}

Fonte: Adaptado de IBGE (2013) e Comissão de Avaliação de Valores Venais de Imóveis (2012).

De acordo com os dados da tabela acima, a figura 2 demonstra a evolução do crescimento populacional, crescimento espacial e número de bairros em percentual acumulado no período de 1990 a 2012.

2 A contagem de habitantes de 2012 é estimada pelo IBGE. 
Figura 2. Evolução do crescimento populacional, crescimento espacial e número de bairros em percentual acumulado no período de 1990 a 2012

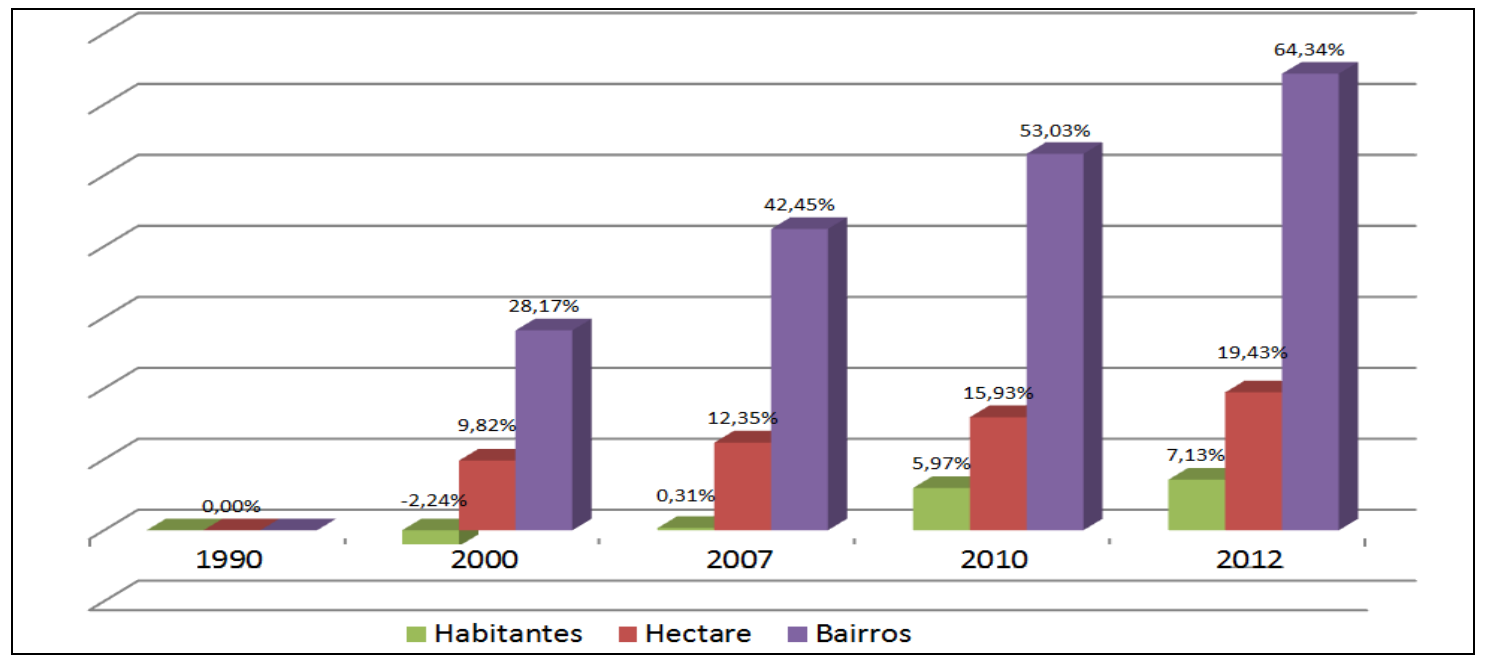

Fonte: Adaptado de IBGE (2013) e Comissão de Avaliação de Valores Venais de Imóveis (2012).

As informações obtidas possibilitam evidenciar que a produção do espaço urbano de Campo Mourão, a intensidade no aumento da criação de novos bairros e, consequentemente, o avanço da área urbana para a área rural não foi acompanhado pelo aumento da população, evidenciando a criação de novos vazios urbanos.

No que diz respeito à correlação existente entre o financiamento público habitacional e a criação de novos bairros, observa-se, na tabela 3 , que existe uma correlação positiva forte entre as variáveis testadas, com significância de 0,01 , indicando que, à medida que as instituições públicas - em especial, a Caixa Econômica Federal - ampliaram a concessão de crédito para o financiamento imobiliário, os agentes imobiliários passaram a se articular com o poder público para a criação de novos bairros, disponibilizando um número maior de lotes à venda do que o necessário para a população estimada no município, aumentando o número de lotes vazios e criando segregação espacial, já que a população beneficiada pelo PMCMV não possui condição de adquirir imóveis próximos à região central.

Dada a complexidade para medir a segregação, conforme exposto anteriormente, optou-se pelo estudo comparativo de dois bairros. A escolha se deu em virtude de que ambos foram criados antes do ano 2000. Portanto, é possível realizar uma comparação histórica entre eles 
Reflexões sobre a relação entre a Expansão Imobiliária e a Produção do Espaço...

e verificar a correlação existente entre o financiamento público, a valorização dos imóveis e a valorização da construção civil. 
Tabela 3. Correlação entre financiamento público e variáveis de valorização (2000/2012)

\begin{tabular}{cc}
\hline Variáveis correlacionadas / Período 2000/2012 & $\begin{array}{c}\text { Índice de correlação } \\
\text { de Pearson (r) }\end{array}$ \\
\hline $\begin{array}{c}\text { Financiamento Público x Número de bairros criados } \\
\text { Financiamento Público x Valorização dos Imóveis - Jardim } \\
\quad \begin{array}{c}\text { Albuquerque } \\
\text { Financiamento Público x Valorização dos Imóveis - Conjunto } \\
\quad \text { Cohapar }\end{array}\end{array}$ & $0,887^{*}$ \\
Financiamento Público x Índice de Preço da Construção Civil & $0,853^{*}$ \\
\hline
\end{tabular}

Fonte: IPEADATA (2012) / Comissão de Avaliação de Valores Venais de Imóveis (2012) / IBGE (2013).

Nota: * a correlação tem significância de $99 \%$ - p-valor > 0,01

Os dados obtidos na tabela 3 possibilitam estabelecer uma correlação entre o financiamento público, o preço dos imóveis de ambos os bairros, e o preço da construção civil, demonstrando que, por um lado, o financiamento público contribui para melhorar o déficit habitacional, mas, por outro, contribui para produzir um espaço urbano ainda mais segregado.

Nesse contexto, apresenta-se a tabela 4 , com os valores comparativos dos bairros:

\section{Tabela 4. Valores médios de valorização no período de $2000 / 2012$}

\begin{tabular}{|c|c|c|c|c|c|c|}
\hline Ano & $\begin{array}{l}\text { Jardim } \\
\text { Albuquerque }\end{array}$ & $\begin{array}{c}\% \\
\text { valorização }\end{array}$ & $\begin{array}{l}\text { Conjunto } \\
\text { Cohapar }\end{array}$ & $\begin{array}{c}\% \\
\text { valorização }\end{array}$ & $\begin{array}{c}\text { Índice de } \\
\text { Preço da } \\
\text { Construção } \\
\text { Civil - PR } \\
\left(\mathrm{m}^{2}\right) \\
\end{array}$ & $\begin{array}{c}\% \\
\text { valorização }\end{array}$ \\
\hline 2000 & $\mathrm{R} \$ 18,00$ & $0 \%$ & $\begin{array}{r}R \$ \\
15,00\end{array}$ & $0 \%$ & $\begin{array}{r}R \$ \\
158,46\end{array}$ & $0 \%$ \\
\hline 2007 & $\mathrm{R} \$ 57,00$ & $95,16 \%$ & $\begin{array}{r}R \$ \\
38,00\end{array}$ & $56,13 \%$ & $\begin{array}{r}\mathrm{R} \$ \\
281,02\end{array}$ & $77,34 \%$ \\
\hline 2010 & $R \$ 173,00$ & $159,43 \%$ & $\begin{array}{r}\mathrm{R} \$ \\
110,00\end{array}$ & $147,43 \%$ & $\begin{array}{r}\mathrm{R} \$ \\
353,52\end{array}$ & $25,84 \%$ \\
\hline 2012 & $\mathrm{R} \$ 280,00$ & $43,59 \%$ & $\begin{array}{r}R \$ \\
170,00 \\
\end{array}$ & $37,11 \%$ & $\begin{array}{r}R \$ \\
406,13 \\
\end{array}$ & $14,85 \%$ \\
\hline
\end{tabular}

Fonte: Comissão de Avaliação de Valores Venais de Imóveis (2012) / IBGE (2013). Nota: O percentual de valorização do preço médio dos imóveis foi corrigido com a taxa de inflação vigente para o período. 
Os dados obtidos na tabela 4 indicam que, no ano 2000, ambos os jardins apresentavam um valor de comercialização semelhante. No entanto, em virtude da produção do espaço e do aumento de financiamento público, ocorreu a valorização dos imóveis dos bairros. Ocorre que a valorização foi mais acentuada no Jardim Albuquerque do que no Jardim Cohapar. Isso se deve ao fato de o Jardim Albuquerque estar localizado mais próximo do centro, oferecendo melhores condições de acesso aos serviços oferecidos na área central.

Para verificar a existência dos vazios urbanos, é apresentado, na figura 4, um comparativo dos mapas dos bairros estudados. No bairro à direita, observa-se o jardim Albuquerque, e à esquerda, o conjunto Cohapar. Nesse caso, é possível verificar que há uma concentração maior de residências no conjunto Cohapar, e uma presença maior de vazios urbanos no jardim Albuquerque.

Por meio do Censo Demográfico do IBGE (2010), a partir dos dados dos setores censitários, também é possível apresentar os indicadores de densidade demográfica e densidade habitacional para os dois bairros estudados, conforme a tabela 5 .

Por meio da tabela 5 e das figuras 3 e 4, verifico-se a existência de uma maior concentração de habitantes no Conjunto Cohapar em detrimento do Jardim Albuquerque. Também verificou-se que as residências são mais aglomeradas e possuem mais habitantes no Conjunto Cohapar, não sendo perceptíveis os vazios urbanos, enquanto que, no Jardim Albuquerque, as residências são mais dispersas e possuem menos habitantes, além de contar com uma presença marcante de vazios urbanos.

Se levados em consideração os valores dos imóveis em cada bairro e a distância que ambos possuem da área central, atrelados aos indicadores habitacionais, é possível inferir que houve uma segregação espacial no Município de Campo Mourão.

Tabela 5. Indicadores habitacionais dos bairros: Jardim Albuquerque e Conjunto Cohapar

\begin{tabular}{ccr}
\hline Indicadores & Jardim Albuquerque & Conjunto Coha \\
\hline Número de Habitantes & $2.221,00$ & $3.810,00$ \\
Espaço territorial em ha & 67,54 & 41,25 \\
Número de Domicílios & 823,00 & $1.254,00$ \\
Densidade Demográfica & 32,88 & 92,36
\end{tabular}


Marcos Clair Bovo, Solange Aparecida Loch, Juliano Domingues da Silva

Densidade Habitacional

2,70

3,04

Fonte: Adaptado do Censo Demográfico do IBGE - Sinopse por Setores (2010).

Figura 3. Mapa do Jardim Albuquerque



Fonte: Plano Diretor (2007) / Google Maps.

Figura 4. Mapa do Conjunto Cohapar

Redes (St. Cruz Sul, Online), v. 20, n 3 - Suplemento, p. 363 - 381, set./dez. 2015383 


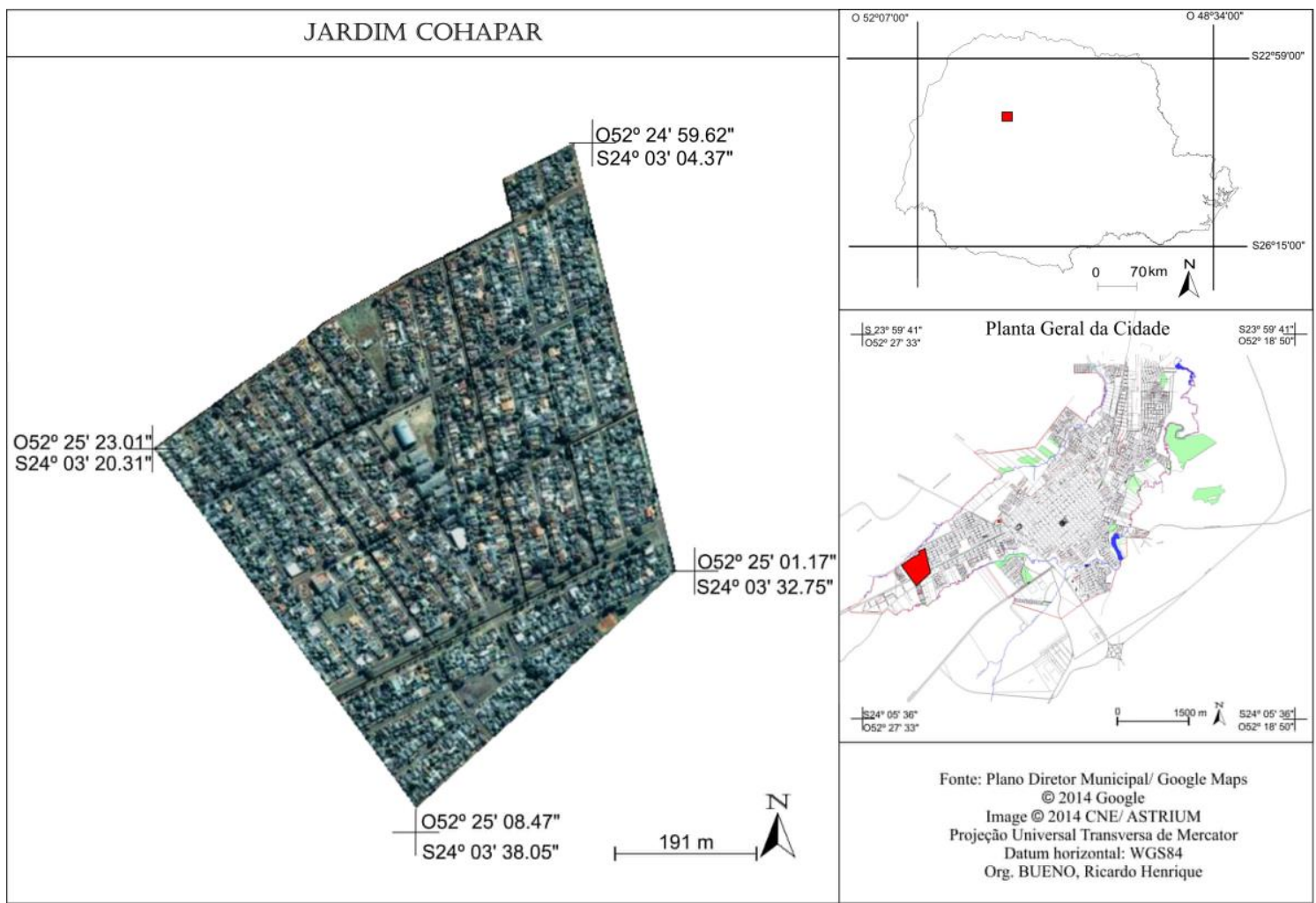

Fonte: Plano Diretor (2007) / Google Maps.

Diante dos achados expostos na análise da produção do espaço do Município de Campo Mourão, verifica-se que as políticas habitacionais não levam em conta as implicações sociais que são impostas na produção do espaço geográfico. Esses achados estão em consonância com as reflexões propostas por Borges (2013), que argumenta que a atuação da politica estatal proposta pelo programa Minha Casa Minha Vida "expressa a continuidade e ampliação de relações sociais e produtivas que favoreçam a plena mercantilização, facilitando a circulação do capital no fortalecimento do capitalismo financeiro". Assim, denota-se que a expansão imobiliária se caracteriza por uma relação capitalista sobre o espaço, tornando-o um elemento estratégico para a acumulação de capital (LEFEBVRE, 2008).

\section{CONSIDERAÇÕES FINAIS}

Com base no referencial teórico apresentado, foi possível constatar que a produção do espaço urbano de um município é influenciada pelos princípios do modo de produção capitalista. Assim, nota-se que o uso da terra é determinado pelo interesse da renda que o proprietário privado pode obter dela. No entanto, apesar de a terra ser 
considerada como mercadoria, ela não é um bem de produção, pois não sofre transformação pelo trabalho. Assim, o dito "lucro" auferido da terra surge da especulação que os proprietários realizam pelo fato de deterem o direito sobre ela e, como foi apontado por diversos autores, grande parcela da população não detém os recursos para garantir a moradia em face do lucro exacerbado. Dessa forma, o direito a moradias a todos os habitantes de um município se contrapõe ao uso capitalista da terra, cabendo, em instância maior, ao Estado garantir os direitos a moradia a todos os cidadãos.

Nesse ponto, destaca-se o financiamento público para alavancar o crédito imobiliário à população, com vistas a diminuir o déficit habitacional. Se, por um lado, o financiamento público possibilita a garantia do direito à moradia à população necessitada, por outro, incentiva a expansão imobiliária dos municípios, com a finalidade da especulação do valor da terra, procurando a obtenção de lucro fácil. Esse quadro foi observado no Município de Campo Mourão, que teve um crescimento elevado no número de bairros no período que coincide com o aumento do financiamento público - em especial, o PMCMV.

Dessa forma, é possível afirmar que o PMCMV contribui para a expansão e especulação imobiliária, fazendo com que o preço dos lotes urbanos tenha uma valorização muito acima da inflação. Isso faz com que o programa de financiamento habitacional não tenha êxito em oferecer habitação para a população mais necessitada, e mesmo aqueles que conseguem obter o financiamento, ficam endividados por um longo período com um valor que não representa o verdadeiro valor da terra, mas, sim, um valor exacerbado, fruto da especulação.

Outro problema levantado na pesquisa é a segregação espacial. Por meio dos estudos de casos dos bairros Jardim Albuquerque e Conjunto Cohapar, foi possível notar que as classes mais altas valorizam mais os seus imóveis com o intuito de manter um "alto padrão" do seu bairro, evitando que a população das classes mais baixas possa ter acesso aos lotes daquele bairro. Assim, a única alternativa que sobra é adquirir lotes mais afastados da área central, como é o caso do Conjunto Cohapar.

Conforme as informações apresentadas nos indicadores habitacionais e nos mapas, o Jardim Albuquerque apresenta um valor por metro quadrado elevado em comparação ao outro bairro, indicando 
uma valorização acentuada com o aumento do financiamento público. Também foi possível observar que o Jardim Albuquerque apresenta muitos vazios urbanos, uma baixa densidade demográfica e baixa densidade habitacional. Enquanto isso, no Conjunto Cohapar, foi possível observar uma alta concentração de domicílios, com indicadores de alta densidade demográfica e alta densidade habitacional.

Com base nesses dados, conclui-se que, devido à lógica de relação do sistema capitalista, o financiamento público, que tem o objetivo de melhorar o desenvolvimento social por meio do aumento de crédito habitacional às pessoas carentes, provoca uma produção do espaço urbano com fins de especulação do valor da terra e, consequentemente, a segregação espacial.

\section{REFERÊNCIAS}

AZEVEDO, S. Vinte e dois anos de política de habitação popular (196486): criação, trajetória e extinção do BNH. Revista de Administração Pública, v. 22, n. 4, p. 107-119, 1988.

Desafios da habitação popular no Brasil: políticas recentes e tendências. In: CARDOSO, A. L. (org). Habitação social nas metrópoles brasileiras: uma avaliação das políticas habitacionais em Belém, Belo Horizonte, Porto Alegre, Recife, Rio de Janeiro e São Paulo no final do século XX. Porto Alegre: ANTAC, 2007.

ANDRADE, L. A. G. Habitação e poder: da Fundação da Casa Popular ao Banco Nacional Habitação. Rio de Janeiro: Centro Edelstein, 2011.

BONDUKI, N. G. Origens da habitação social no Brasil. Análise social, v. 29, n. 3, p. 711-732, 1994.

BASTOS, N. S. M de. A moradia possível: a trajetória das políticas habitacionais no Brasil. Sociedade e Território, Natal, v. 15, n. 2, p. 81106, 2001. 
BORGES, V. F. Reflexões sobre a política pública de habitação: do Banco Nacional de Habitação ao Programa Habitacional Minha Casa, Minha Vida. Boletim Gaúcho de Geografia, v. 40, n. 2, p.141-154, maio, 2013.

CARLOS, A. F. A. Dilemas urbanos. São Paulo, Contexto, 2005.

CASTELLS, M. A Sociedade em rede. São Paulo, Paz e Terra, 1999.

COMPANS, R. Empreendedorismo Urbano: entre o discurso e a prática. São Paulo: Editora UNESP, 2005.

COMISSÃO DE AVALIAÇÃO DE VALORES VENAIS DE IMÓVEIS. Avaliação do valor venal de imóveis urbanos por bairro. Campo Mourão: 2012

CORRÊA, R. L. O espaço urbano. 4. ed. São Paulo: Ática, 2002.

COSTA, J. C. Desenvolvimento econômico brasileiro contemporâneo e a Caixa: o papel do FGTS. In: COSTA, J. C. et al. (orgs). O desenvolvimento econômico brasileiro e a Caixa: trabalhos premiados. Rio de Janeiro: Centro Internacional Celso Furtado de Políticas para o Desenvolvimento / Caixa Econômica Federal, 2011.

D'AMICO, F. O Programa Minha Casa, Minha Vida e a Caixa Econômica Federal. In: COSTA, J. C. et al. (orgs). O desenvolvimento econômico brasileiro e a Caixa: trabalhos premiados. Rio de Janeiro: Centro Internacional Celso Furtado de Políticas para o Desenvolvimento / Caixa Econômica Federal, 2011.

FERRAUDO, G. M.; LOUZADA-NETO, F.; FERREIRA, J. F. Determinação do valor de mercado de lotes urbanos: estudo de caso - município de São Carlos, São Paulo, Brasil. Rev. Bras. Biom., São Paulo, v. 28, n. 4, p. 52$65,2010$.

FERREIRA, G. A natureza (dos) nos fatos urbanos: produção do espaço e degradação ambiental. Desenvolvimento e Meio Ambiente, v. 3, n. 1, p. 33-51. Editora da UFPR: jan./jun. 2001. 
HAIR JR., J. F.; ANDERSON, R. E.; TATHAM, R. L; BLACK, W. C. Análise multivariada de dados. 5. ed. Porto Alegre: Bookman, 2005.

IBGE. Instituto Brasileiro de Geografia Estatística. Pesquisa de Orçamentos Familiares de 2008-2009. Disponível em: www.ibge.gov.br/home/estatistica/.../2008_2009/POFpub-licacao.pdf. Acesso em 01 jul. 2013.

Censo Demográfico 2010 - Sinopse por setores. Disponível em: http://www.censo2010.ibge.gov.br/sinopseporsetores/. Acesso em 01 jul. 2013.

- Estimativas populacionais para os municípios brasileiros em 01.07.2013. Disponível em: http://www.ibge.gov.br/home/estatistica/populacao/estimativa2013/d efault.shtm. Acesso em 05 jul. 2013.

IPEADATA. Instituto de Pesquisa Econômica Aplicada. Operações de crédito na Habitação. 2012. Disponível em: http://www.ipeadata.gov.br/. Acesso em: 23 set. 2012.

KRAN, F.; FERREIRA, F. P. Qualidade de vida na cidade de Palmas - TO: Uma análise através de indicadores habitacionais e ambientais urbanos. Ambiente \& Sociedade, v. 9, n. 2, p. 1-33, jul./dez. 2006

LEFEBVRE, H. Espaço e Politica. Belo Horizonte: Editora UFMG, 2008.

MACHADO, J. R.; MENDES, C. M. A incorporação imobiliária e o mercado de imóveis em Maringá: Supervalorização ou Superexploração?. Revista Percurso - NEMO. Maringá, v. 4, n. 1, p. 99-114, 2012.

PORTELLA, A. A. et al. Segregação social e densidade urbana: o geoprocessamento como instrumento de análise. In: X Encontro Nacional da ANPUR. Anais... 2003. Disponível em $<<$ http://www.anpur.br/anais $>>$ Acesso em 23 jun. 2013. 
POSTALI, V. B.; MENDES, C. M. A importância do circuito inferior na (auto) produção da casa própria em Londrina/PR/Br: estudo de duas ocupações urbanas irregulares. Revista Geográfica de América Central, v. 2 , n. $47 \mathrm{e}, 2011$.

PLANO DIRETOR MUNICIPAL CAMPO MOURÃO/PR. Secretaria de Estado de Desenvolvimento Urbano, Serviço Social Autônomo. ParanaCidade, 2007.

RIBEIRO, L. C. Q. Segregação Residencial e Políticas Públicas: análise do espaço social da cidade na gestão do território. In: RASSI NETO, E.; BÓGUS, C. M. (orgs). Saúde nos aglomerados urbanos: uma visão integrada. Brasília: Organização Pan-Americana da Saúde, 2003.

SINGER, P. O uso do solo urbano na Economia capitalista. In MARICATO, E. (org). A produção capitalista da casa e da cidade no Brasil industrial. São Paulo; Alfa-Ômega, 1979.

SABATINI, F.; SIERRALTA, C. Medição da segregação residencial: meandros teóricos e metodológicos e especificidades latino-americana. In: CÁCERES, G.; SABATINI, F. (orgs). Los barrios cerrados en Santiago de Chile: entre la exclusión y la intregración social. Santiago-Chile: Instituto de Geografia, PUC, 2004.

SANTOS, M. Totalidade ao lugar. São Paulo: Editora da Universidade de São Paulo, 2005.

VILLAÇA, F. Espaço intra-urbano no Brasil. São Paulo: Nobel, 1986.

Submetido em $17 / 04 / 2014$

Aprovado em 26/11/2015

Sobre os autores

Marcos Clair Bovo

Doutor, Professor adjunto do Colegiado do Curso de Graduação em Geografia e do Programa de Pós-Graduação Interdisciplinar Sociedade e Desenvolvimento da 
Universidade Estadual do Paraná, Campus de Campo Mourão, Líder do Grupo de Estudos Urbanos da Fecilcam.

E-mail:mcbovo@yahoo.com

Solange Aparecida Loch

Graduada, Curso de Geografia (UNESPAR/Campus de Campo Mourão).

E-mail: solangeloch@yahoo.com.br

\section{Juliano Domingues da Silva}

Mestre, Programa de Pós-graduação em Administração da Universidade Estadual de Maringá (PPA-UEM), Professor Assistente do Departamento de Administração da Universidade Estadual de Maringá (DAD/UEM).

E-mail: juliannodomingues@yahoo.com.br 